THE RING 35 (2013) DOI 10.2478/ring-2013-0001

\title{
METHODOLOGICAL PROCEDURE FOR PRE-INVESTMENT WIND FARM ORNITHOLOGICAL MONITORING BASED ON COLLISION RISK ESTIMATION
}

\author{
Przemysław Busse
}

\begin{abstract}
Busse P. 2013. Methodological procedure for pre-investment wind farm ornithological monitoring based on collision risk estimation. Ring 35: 3-30.

Even though the proportion of wind farm victims compared to general bird species mortality is relatively low, there is necessity to limit direct and indirect losses to the bird populations caused by this kind of human activity. Estimation of threats to the birds resulting from building of wind farms is a very difficult task and it must take into account several constrains. The basic task is to build farms in localities that are the safest to birds. This can be achieved by pre-investment monitoring and direct observations at the spot and then evaluation of potential threats and risks. Field methods typical for the studies on bird populations are usually applied in such monitoring. The procedure described below includes four steps: screening (starts the process and sets preliminary constrains of the location), monitoring (standardised data are collected at the location), estimations of potential collision risk and evaluation of the location.

The key parameters determining collision risk of bird species are: (1) the number of individuals utilising the monitored area in different seasons, (2) air space utilization (height and directions of flights), as well as (3) characteristics of the species behaviour. The starting data set contains: species name, number of individuals, height of flight (three layers - below, in, above the rotor), and distance from the observer. The final estimation of the collision index (the most probable number of collisions per turbine a year) is based on (1) estimation of the total number of individuals that use the defined area during a year and (2) estimation of probability that the individual will collide. In the latter (i.e. 2) the most important is that birds can actively avoid passing through the rotor swept (active avoidance rate) and that even birds, which crossed the rotor swept area not necessarily will be killed. Calculations are performed for each species separately and then are summarised to get the farm index as well as season indices. Some values of indices for raptors studied at 76 localities in Poland are given in the table.

The final evaluation of the site is made as shown in a parametric analysis table, discussion of cumulative and barrier effects and the discussion of species specific risk to species of high conservation concern.
\end{abstract}


P. Busse, Bird Migration Research Foundation, Przebendowo, PL-84-210 Choczewo, Poland; e-mail: busse@wbwp-fund.eu

Key words: wind farm, pre-investment monitoring, birds, collision estimation, methods, cumulative risk, barrier effect, raptor collision indices

\section{INTRODUCTION}

Estimation of threats to the birds resulting from building of wind farms is a very difficult task and it must be performed with awareness of several different constrains. Wind farm building has a few decades of development. After first farms were built, the problem of birds' collisions attracted a lot of attention. However, observations were done using very different methods, in highly differentiated localities and in quite variable time periods. Because of that, results were quite accidental and incomparable - there were either no victims recorded in the long term studies or even more than 60 per turbine in a year. Such high mortality alerted the experts. The problem was when they were generalized as a common property of wind farms - particularly for the mass-media these were "news" highlighted for the public. In the first years of the century the papers summarising the results of collected data were published. The most comprehensive was the book by Hötker et al. (2006). The authors claimed that despite of losses to the birds caused by wind farms the overall influence on bird populations was generally not important: "According to recent information, it seems that in the USA the mortality rates of birds due to collisions at wind farms is negligible (Erickson et al. 2001)" and "... - it is not thought that wind turbines cause significant increases in annual mortality rates". The relatively low influence of wind farms on bird populations is shown in the table (see Table 1) given after Erickson et al. (2001). For small birds one can add a huge share of birds, either local or migrating, killed by domestic cats, e.g. during spring migration at the Hel Peninsula, the southern Baltic coast, these losses were estimated at 10000 birds (M. Skakuj, pers. comm). Some people applied modelling to show that even slight additional deaths caused by wind farms could be seriously harmful to bird populations. Hötker et al. (2006) when discussing results obtained with the PVA model, which was applied e.g. in the Vortex programme, stressed that the model assumed that there was no density related mechanisms that balanced natural and additional losses to the populations. Density-dependent mechanisms are the basic rule of the population ecology and without their homeostatic directed influence populations would go to a huge overgrowth or extinction. It should be mentioned here that the basic idea of the Vortex programme is, as its subtitle says (Fig. 1): "A stochastic simulation of the extinction process" so, it is really not the study programme but a demonstration tool: "what would be if we assumed extinction of the species". The programme requires values of around 40 parameters, that for most of bird species are not known at all or surely not known for a defined local population. Thus, in practice, these parameters must be arbitrarily assumed with no guaranty that they are stable in the natural conditions over tens of years covered by 
the programme estimations. Any such assumption could change the result to a great extent and made it unacceptably biased.

Table 1

Estimates of numbers of bird victims from collisions with anthropogenic structures in the USA (after Erickson et al. 2001)

\begin{tabular}{|l|l|}
\hline \multicolumn{1}{|c|}{ Cause } & \multicolumn{1}{c|}{ Estimated number of casualties } \\
\hline Traffic & $60-80$ millions \\
Buildings and windows & $98-980$ millions \\
Electricity pylons and cables & 174 millions \\
TV and communication towers & $4-50$ millions \\
Wind turbines & $\mathbf{1 0 - 4 0}$ thousands \\
\hline
\end{tabular}

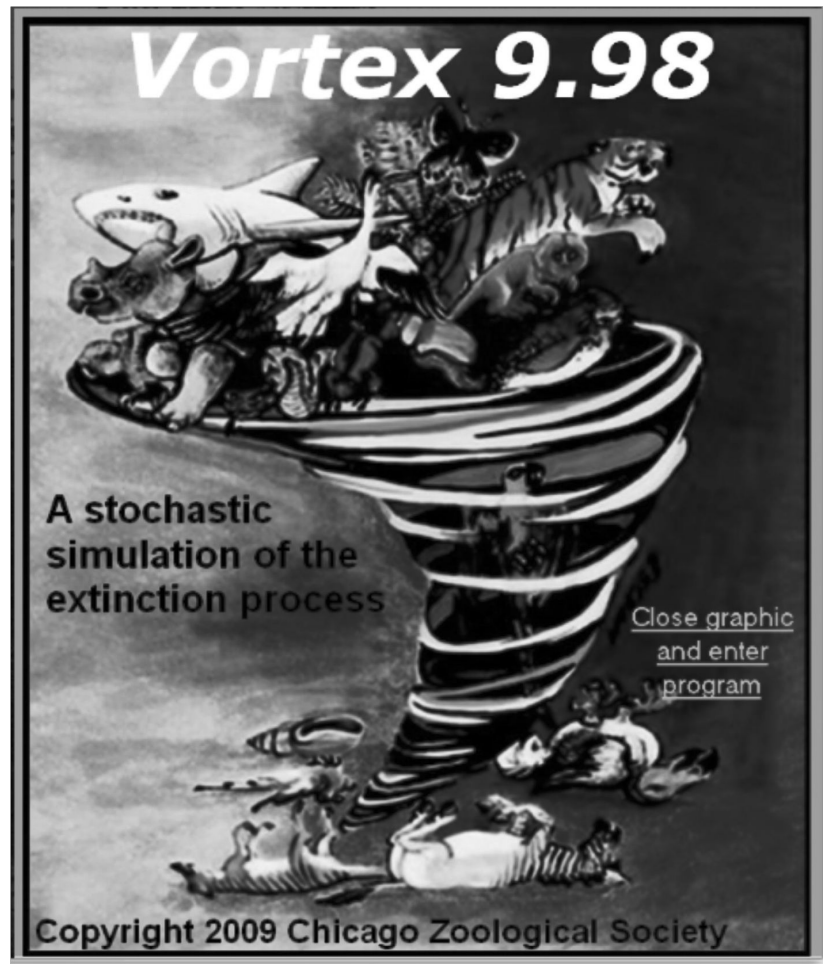

Fig. 1. The title screen of the VORTEX programme - „A stochastic simulation of the extinction process".

Independently of the actual proportion of wind farm victims in a general bird species mortality there is necessity to limit direct and indirect losses to bird populations caused by the wind farms. Generally, the most important is the correct selection of localities intended for building wind farms. The worst examples from the past showed that there are some localities which must be excluded from the wind farm develop- 
ment, like: migration bottle-necks (some coastal regions, mountain passes), areas of high concentration of breeding birds or those, where especially vulnerable species (e.g. vultures, White-tailed Eagle) regularly breed or concentrate. However, there is a lot of localities where the potential danger is lower, but could be highly varied. So, the main task of pre-investement monitoring is to estimate and evaluate risk and point out possible methods of reduction of potential risk, when the wind farm will be build.

The main problem is how to proceed during pre-building phase - which methods known from the population studies would be useful - and which inapplicable to that specific, practical task: to estimate how much safe - or unsafe - is the defined area taking into account an investor's plan including defined number of turbines - turbines characterised by the defined main parameters: height of the tower, diameter of the rotor, engine power and a maximum rotation frequency.

The task for the efficient procedure is setting appropriate field methods that could follow birds density and behaviour at the place of concern over all seasons, while the collected data could be combined into compatible parameters. The compatibility does not mean that methods applied have to be exactly the same in every place, but still they must have common elements, e.g. known time spent on observations (independently of whether these point or transect observations). If the field routines are compatible enough there is possibility to evaluate data using different analytical methods, but still will be a chance to re-evaluate them and to compare with other localities the best way to decide whether the location is better - or worse - than others. The worst solution is to use a few independent and not compatible "modules" (PSEW 2008) that originated from different scientific methods tailored to totally different goals of the study.

The evaluation stage could be somewhat flexible and be more or less formalised. Generally, evaluation could be given either as comments on monitoring results and recommendation according to the experience of the expert or estimation according to modelling, i.e. calculations based on the model of an influence of different parameters (based on the local data) on the final probability of collision. The best discussion of these options can be found in the paper by Smales (2006) - (see Fig. 2). While Scottish Natural Heritage (e.g. SNH 2011) already developed and updated the Band's collision risk model.

The procedure described below includes four steps: screening (starts the process and sets preliminary constrains of the location), monitoring (standardised data are collected at the location), estimations of potential collision risk and evaluation of the location.

\section{SCREENING - MONITORING SCHEME}

To prepare plan of screening and the location-specific observation scheme several details and visit at the site are essential: (1) topographic map of the location showing delimited area of the planned farm, approximate number of turbines and their basic parameters (type, power, height of the tower and diameter of the rotor), (2) already 


\subsection{BACKGROUND TO MODELLING AS A TOOL IN RISK ASSESSMENT}

The fundamental objective of modelling of risk is to provide a rigorous process by which probability can be assessed in a manner that can be replicated.

When making predictions of risk using a model, the rationale behind the predictions is explicitly stated in the mathematics of a model, which means that the logical consistency of the predictions can be easily evaluated. This is the case regardless of the type of model used.

The only real alternative to the use of a model is the use of subjective judgement to predict risks. Compared to subjective judgement, the explicit nature of inputs and rigour entailed in modelling makes models more open to analysis, criticism or modification when new information becomes available. Although there may be assumptions used and some arbitrary choices made when deciding on the structure and parameters of a model, these choices are stated explicitly when using a model but this is difficult to do when making subjective judgements. The assumptions underlying a model can be tested. Models can be used to help design data collection strategies. They can also help to resolve and avoid inconsistencies, and the rigorous analysis of data can help to clarify thoughts. Models are often also valuable for their heuristic capacities, by focussing attention on the important processes and parameters when assessing risks (Brook et al., 2002). These benefits are difficult, if not impossible to achieve with subjective judgement. Another drawback of subjective judgement is that it may lead to biased predictions of risk, and the biases vary unpredictably among people (Tversky and Kahneman, 1974; Ayton and Wright, 1994; Gigerenzer and Hoffrage, 1995; Anderson, 1998). The predictions of models tend to be less biased (Brook et al. 2000, McCarthy et al. 2004). There are thus considerable benefits to be gained by employing a model when assessing risk.

Fig. 2. Citation from the paper by Smales (2009). The rationale for the modeling of the monitoring valuation observations. 
collected data (e.g. ecological validation of the county, if available), (3) distribution of nature protected areas in vicinity (National Parks, nature reserves, Nature 2000 sites) and (4) a visit at the site of an experienced ornithologist to prepare photographic documentation of the area, preliminary setting of local habitat peculiarities and do interviews with local people.

When working on the plan of screening quality of available sources of data should be considered. Frequently local sources, even the data in Standard Data Forms of NATURE 2000 sites, can be of low quality, so the evaluation at the spot is crucial. To cover main necessary data there is useful to pass through some points listed in check-lists shown in Tables 2 and 3.

Table 2

Evaluation of expected risks (example)

\begin{tabular}{|l|c|c|c|}
\hline \multirow{2}{*}{\multicolumn{1}{|c|}{ Parameter of locality }} & \multicolumn{2}{c|}{ Estimated probability of risk } \\
\cline { 2 - 4 } & Low & Average & High \\
\hline Birds vulnerable (EU App. I, Red Book) & $\mathrm{X}$ & & \\
\hline Breeding raptors & & $\mathrm{X}$ & \\
\hline Migrating/wintering raptors & $\mathrm{X}$ & & \\
\hline Breeding colonies & $\mathrm{X}$ & & \\
\hline Local assamblages out of breeding season & $\mathrm{X}$ & & \\
\hline Migration streams & & & $\mathrm{X}$ \\
\hline Relations with protected areas & $\mathrm{X}$ & & \\
\hline Number of turbines/potential cumulation of risks & $\mathrm{X}$ & & \\
\hline
\end{tabular}

Table 3

Estimated probability of the collision risk in different seasons (example)

\begin{tabular}{|l|c|c|c|}
\hline \multirow{2}{*}{\multicolumn{1}{|c|}{ Season }} & \multicolumn{3}{c|}{ Estimated probability of risk } \\
\cline { 2 - 4 } & Low & Average & High \\
\hline Spring migration (1 III-30 IV) & & & $\mathrm{X}$ \\
\hline Breeding period (1 V-30 VI) & & $\mathrm{X}$ & \\
\hline Post-breeding period (1 VII-31 VIII) & $\mathrm{X}$ & & \\
\hline Autumn migration (1 IX-15 XI) & & $\mathrm{X}$ & \\
\hline Wintering (16 XI-28 II) & $\mathrm{X}$ & & \\
\hline
\end{tabular}

Number of observation days per season is set according to probability of potential risk - the higher risk is expected the more observation days should be planned. As a minimum is used around 30 controls within a year. Some special comments could be specified here, as e.g. the area of mapping the nests outside the area, additional evening observations etc. These specific requirements can be updated (changed or extended) during the monitoring process.

The number of observations as well as their time schedule over the seasons are set according to estimated time of expected risks and the observer should adapt his/her activity in the field to the table prepared by the expert-ornithologist (e.g. Table 4). 
Table 4

Distribution of observation days per season (the basic time-table)

\begin{tabular}{|l|c|c|}
\hline \multicolumn{1}{|c|}{ Season } & $\begin{array}{c}\text { Duration of the season } \\
\text { (days/weeks) }\end{array}$ & $\begin{array}{c}\text { Number } \\
\text { of regular controls }\end{array}$ \\
\hline Spring migration (1 III-30 IV) & $60 / 8$ & $\mathbf{6}$ \\
\hline Breeding season (1 V-30 VI) & $60 / 8$ & $\mathbf{6}$ \\
\hline Post-breeding season (1 VII-31 VIII) & $60 / 8$ & $\mathbf{6}$ \\
\hline Autumn migration (1 IX-15 XI) & $75 / 10$ & $\mathbf{8}$ \\
\hline Wintering (16 XI-28 II) & $105 / 14$ & $\mathbf{7}$ \\
\hline TOTAL & & $\mathbf{3 3}$ \\
\hline
\end{tabular}

Defined days of the controls are not fixed in the monitoring scheme, but the observer must follow basic rules: (1) time interval between two regular observation days cannot be less than 5 days and more than 15 days (even in the seasons, when the predicted number/density of birds is lower than average), (2) controls cannot be performed during bad weather conditions (fog, continuous rainfall or snow, very strong wind).

\section{MONITORING}

\section{Assumptions}

Wind farm location monitoring is the special method applied to practical evaluation of a certain site for the certain wind farm (area covered, type and number of turbines). It is based on the scientific research methods, but not necessarily being identical with them as the goal is limited to answer to the question: "how far the site is safe to the birds utilising this area". Therefore all bird species (1) nesting within the studied area, (2) nesting outside the monitored area, but using it regularly for feeding or passing over when heading to adjacent feeding grounds, (3) using the location as transitional/stop-over place (flying over and stopping there) during migration and outside the breeding season (seasonal migrations, dispersion and wintering) must be monitored. Parameters which are important particularly for first two groups are the collision rate and loss of breeding/feeding sites. All risks are limited to the very local population. Here discussion of risks must be limited to a very narrow group of birds at and around the site as the influence of the farm drops rapidly with the distance between the farm and the nest (relative risk is proportional to inverse of a distance to the second power $-1 /$ dist $^{\square}$ : this is a simple geometrical relation). The last group is exposed mainly to collisions on migration and, in very limited extent, to loss of exceptionally good feeding/resting places that depend on a level of specialisation of the species. If the site is of a low or an average ecological value the birds easily can move farther, at least in Europe. In that case the risk should be discussed in relation to the size of population breeding on a huge area, many thousands square kilometres and usually at least hundreds to thousands kilometres away. So, the same value of estimated collision rate could have very different value for the population. 
The key parameters determining collision risk of bird species are: (1) the number of individuals utilising the monitored area in different seasons, (2) air space utilization (height and directions of flights), as well as (3) characteristics of the species behaviour. Consequetly information obligatory noted for every bird/flock observed is as follows: number of individuals, direction and height of flight, distance from the observer as well as details of the behaviour (feeding, resting etc.). As supplementary information, like location of observed birds or their flocks, should be given on the map, if they are regularly observed in particular place because of habitat properties (e.g. small water bodies, meadows within arable area, groups of trees).

For species of a greater conservation value (species listed in UE Appendix I, Red Book species) the knowledge about their breeding sites within and ca $2-3 \mathrm{~km}$ around the monitored area is essential for more detailed analysis of observation data. All these species should be located and pointed on the map both during basic controls (esp. transect controls) and special searches beyond standard observation time.

During the bird migration periods, when birds usually are not settled in defined places (e.g. pieces of a forest or bushes as well as fields or meadows) the best solution is to carry out observations from a fixed post that is located usually in a centre of the planned farm and it allows good visibility in all directions. However, because of influence of current weather conditions, especially the wind force and direction, the observer can change this fixed point to another that allows to see the passage of birds better or to count individuals which landed on the site not visible from the standard post. During winter many birds are in flocks and concentrate in certain places, e.g. straw stacks, hunters' feeders etc. So, in that time observations are more effective if performed during a slow walk through the monitored area. This is so called "transect" or "moving observation point" - the procedures of noting and observation are the same as during the observations from the fixed post. The idea is the same - to learn on avifauna of the area of the future farm as accurately as possible.

In the period covering spring, breeding and post-breeding dispersion seasons the transect style of observations is the basic method as the breeding birds stay close to their nests and local feeding grounds. However, as in early spring some birds already start to breed, while others still migrate, the observer must adjust the observations to current situation and combine two methods of work.

Use of the fixed point and transect observations with the obligatory noting the time of work is the only solution that allows combining both procedures into one set of data that are intended to answer the question: "How many birds will be exposed to the risk when the farm will be built?" - this is the main goal of pre-investment monitoring.

Because of the above goal of pre-investment monitoring, some methods applied to certain scientific ecological problems, even called as "monitoring" methods, are not applicable to the pre-investment monitoring. The best example is the Common Birds Census. This is a popular project intended to follow distribution and population trends of common birds within the area of a country size. The project is based on work of volunteers and the method is extremely simplified: on a square $1 \mathrm{x} 1 \mathrm{~km}$ selected randomly within the country area, two fixed parallel transects are controlled twice during breeding season and all birds found/observed are noted. Any single 
square data are extremely accidental because of the method of sampling (short transect, different habitats within the transect, two controls only - thus some weather variation, observer quality and location of observations days within the season). The CBS data are totally incompatible with other pre-investment monitoring observations and its standards are well below the acceptable level. Originally this method is used for completely different goals and can be evaluated only when there are at least hundreds or thousands of repetitions over a wide area (species distribution and relative numbers) and carried out by many years (population trends). Similarly, constant transects used in pre-investment monitoring do not bring data more useful than transects carried out freely, according to actual weather conditions - the birds are much more flexible in behaviour than bats for which monitoring must include micro habitat variation.

\section{Monitoring routine}

Fixed point observations - the main rules

1. These are visual observations of active passage and feeding/resting activity of birds visible from the fixed point. The radius of identification and bird counting depends on behaviour and the size of individuals - small birds and those sitting on the ground can be identified at shorter distance (usually to 100-200 m) than large, flying birds (up to around $500 \mathrm{~m}$ over the ground, while large eagles even at more than $1 \mathrm{~km}$ distance). So, the distance to the observed birds gives some additional information about probability that the bird could be at risk of the collision - it is simplification as in this case the observer "is the turbine". "Fixed point" does not mean that it is fixed for ever - during migration birds adapt their behaviour to changing weather conditions, so the stream of migrating birds can change its course according to wind power and direction and the observer must follow them to have the best possible visibility of passing birds.

2. The observations should start not later than 2 hours after a sunrise and last for 4-6 h. All birds ought to be noted throughout all this time, but in 3 first hours main attention should be focused on passerines, while later on raptors, that are more active later in the day. In the notebook the time should be noted every 15 minutes, but this is only additional information and the same bird (e.g. gliding over the area) should not be noted every 15 minutes: raptors, that frequently behave like this, need to be noted once per hour (there is convention that the bird noted stay at the place one hour). Do not note several times the same bird sitting on the nest (e.g. Stork) or birds staying at the place (when you are sure that the flock of eg. 7 cranes is the same as the flock observed 15 minutes earlier).

3. In all observed birds their number, details of behaviour - flight: direction and height (in three layers: below the lowest rotor level, within the rotor diameter and above the highest rotor level) - should be noted. An additional information which can be noted is where to or from where birds fly (e.g. "to feeding ground", "from roosting place", etc.). Data/information should be written down in special notebooks with appropriate columns using standard codes (e.g. for species 5- or 6-letter codes - Busse 2000). 
4. Weather data are noted in special columns and these are: temperature, cloudiness, visibility, precipitation, wind (direction and power). If these parameters change during observation time they should be updated. Observations should be stopped if extreme weather conditions make them ineffective (heavy rain or snow, fog, storm).

Transect

The transect route can be flexibly changed according to the situation - weather conditions, birds' behaviour, crop development, farmers activity etc. However, it must be inside of the planned farm area (not closer to the border than $300 \mathrm{~m}$ ). Time of the transect control should be noted and it must be more or less the same as the standard fixed point observation. Other rules apply to both types of observations. This makes the transect and fixed point data comparable, thus they can be evaluated together.

\section{Additional observations}

During breeding season additional observations should be performed, i.e. looking for breeding birds of the species of special protection status both at the location of the planned farm and in the buffer zone $2-3 \mathrm{~km}$ from the monitored area. The size and limits of the buffer area depend on local situation: distribution of forests, lakes, wet meadows etc. in relation to the planned farm. This is much more efficient than setting formal, e.g. 10x10 km squares. The nests which were found, should be mapped.

Night controls are sometimes recommended, however, this a very controversial practice - much effort while a little useful information. During breeding time they could give some information about owls or Corncrakes, while in migration time they are totally useless: during nocturnal migration birds fly at high altitudes, usually well above $300 \mathrm{~m}$ and when in migratory flight they cannot collide. The only situation of collisions (sometimes quite high) are in nights with heavy rain, snow or fog, when visual observations are totally ineffective and such nights are rare (a few per year). A little information that can be collected during scarce nocturnal controls is not worth of the effort: out of three owl species of the high protection rank (Eagle Owl Bubo bubo, Short-eared Owl Asio flammeus and Tengmalm's Owl Aegolius funereus) two last were very scarce within reports of victims at wind farms (Dürr's Database 2012 three and one individuals in Europe), while more vulnerable Eagle Owl (25 collisions reported in Europe) is carefully followed by site protection programmes and its distribution is known without additional sporadic controls.

\section{EVALUATION OF THE MONITORING DATA}

\section{The basic idea and general assumptions}

Solving the problem of collision risk of birds at the wind farm is in reality the problem of estimation of probability that the bird flying within the farm area will collide with any of turbines working there.

The probability for one individual is very low but surely higher than zero. For population of birds visiting the farm area it depends on the number of birds there and 
individual risk value: the more birds in risk the higher is the risk of collision. Individual risk was not taken under consideration, despite the fact that there are species specific differences in the risk of collision. Or rather as the individual risk it was used probability that the bird will be hit while it passes through the rotor swept. This was because of some species are especially vulnerable to this danger (e.g. vultures and the White-tailed Eagle), while some - are not.

The first general analyses of the problem limited it to two elements (Band et al. 2007):

"Number of birds colliding per annum = number flying through rotor (Stage 1) $x$ probability that the bird flying through rotor will be hit (Stage 2)"

To use this formula one needs following properties of the birds:

"1. The time each target species spends flying over a defined survey area.

2. The relative use of different parts of the survey area by each target species.

3. The proportion of flying time each target species spends at turbine rotor height".

The first and third condition could be estimated rather easily. Although they must be taken from observations using any sampling method - observations carried out by "X" hours daily (not all the day length) and made in some "Y" intervals (not all the 365 days a year). The other property - height of flight - can be, in practice, estimated once per observed bird/flock because following many objects simultaneously and during longer time is impossible for the observer (this could be done by sophisticated radar software). The same comment could be applied to the second property of the field observation. So, the "Stage 1" could give some estimations - not the exact data (and this we must keep in mind when discussing the results).

The proposed "Stage 2" considers the last stage of the risk estimation process: the probability of being hit when the flying bird crosses the rotor swept area (hit, i.e. killed or seriously injured or to pass through safely). This probability estimation is based on the relationships between characteristics of the bird (bird size, speed and characteristics of flight) passing through the rotor swept area and turbine properties (blades dimensions and rotation speed). According to the calculations for a quite large birds (Greylag Goose Anser anser and Hen Harrier Circus aeruginosus) probability to be hit when passing the rotor area is rather low -12.3 and $17.9 \%$ (Whitfield and Madders 2005).

In the discussion section of the paper, the authors (op. cit.) mentioned that according to their personal experience ("M. Madders \& D. P. Whitfield unpublished data") there is also another parameter in collision risk estimations - avoidance rate, that is, however, "...difficult to detect...". This is not only true, but this is a very important element in this problem analysis - birds are not blind and deaf. Initially this parameter was commonly assumed at $95 \%$ (probability 0.95 ) of birds which avoid to fly through the rotor, then it was estimated at $98 \%$ for eagles (Percival 2007), 99\% for harriers (Whitfield and Madders 2005), while 95\% mentioned above was claimed as "unrealistic" (Percival 2007). In the early stage of discussion on avoidance rate Chamberlain et al. (2006) claimed that the assumption of avoidance rate had extremely high influence on results. They reported that change of this parameter by $10 \%$ resulted in $2000 \%$ change in the estimated collision rate. Some authors cited this statement as an argument that the modelling using the avoidance rate parameter must be completely 
disregarded. In fact, this statement was based on misunderstanding of the role of avoidance rate in estimation of the collision rate: calculations have to consider probability that the bird will fly through the swept area $(P)$ - and not that it will avoid to do such flight $(U)$. Thus, the value of the parameter used in calculations $(P)$ is:

$$
\begin{gathered}
P=1-U \text {, instead of assumed value of avoidance rate }(U)-\text { so, } \\
P=0.01 \text { when } U=0.99 .
\end{gathered}
$$

If we understand the difference, the variation related to this parameter has the same level as other parameters taken under consideration. The same conclusion was published in Scottish Natural Heritage report 2011 (SNH 2011). The average $U$ value (for 11 papers) is $99.75 \%$ with a standard deviation $0.22 \%$. This value shows that generally estimation of avoidance rate is much higher than it was assumed at the beginning. The best example is a history presented by Fernley (Fernley et al. 2006, Fernley 2008) about estimation of geese collision rate where instead of 175 estimated victims (assumed avoidance rate 95\%), in reality - from real data - there was 3 victims (that means avoidance rate at the level of 99.99\%). Even for the Golden Eagle the avoidance rate was estimated at 99.4 (Fernley 2009). Thus, Scottish Natural Heritage reports give current updates of avoidance rates.

\section{The procedure applied to estimations}

The procedure presented below has been developed since 2008 when first wind farms in Poland were planned and discussions about methods of pre-investment bird monitoring started. These were listed in a preliminary publication (PSEW 2008) and further development was expected, as there was a number of controversies particularly to the methods which should be applied. Since that time experience gained have resulted in several schemes, one of which is presented here on a basis of more than 120 assessments performed by the author using the software, which was developed and still upgraded (WindRisk 7.6 by P. Busse).

The starting data set includes: species name, number of individuals, height of flight (three layers - below, in, above the rotor), and distance from the observer. Direction of flight, noted by the observer, is not used in calculations as this needs additional data about wind-rose that are not available yet.

The final estimation of the collision index (the most probable number of collisions per turbine a year) derives from (1) estimation of the total number of individuals that use the defined area during a year and (2) estimation of probability that the individual will collide.

All calculations are performed for every species separately and then summarised for the farm index (as well as season indices).

1. Estimation of the total number of individuals of every species that use the defined area during a year

1.1. The noted birds represent a real numbers of individuals using the area in the time the observer spent on observations (according to hours given in the note-book). To have total daily numbers these numbers are recalculated into the daily value in two steps - recalculation to the light part of the day and correction for the average diurnal activity of birds. In spring (see Table 3) day length is assumed to be 12 hours on average, then in breeding $-18 \mathrm{~h}$., dispersion, autumn migration $-12 \mathrm{~h}$. and winter $-6 \mathrm{~h}$. 
An example (1): in spring, during 4 h. 100 individuals of a certain species were observed; recalculation for the daily number $(100 / 4) * 12=300$ is overestimated, as observations were performed during the highest activity of birds, thus they were easier to record; then, corrected by multiplication of 0.8 (empirical activity coefficient) gives more real value - 240 .

An example of recalculation for the raptor birds activity is shown at Figure 3 - the result $N_{\square}$ is still conservative (a little overestimated).
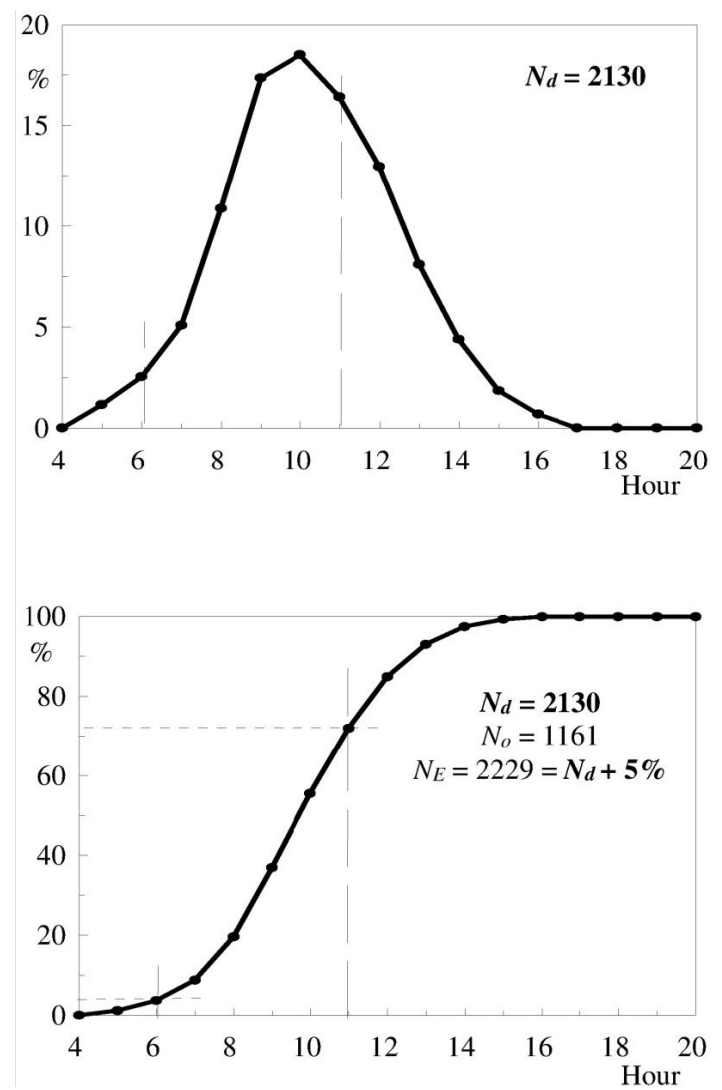

Fig. 3. Recalculation of results of 6.00 to $11.00 \mathrm{~h}$. observations $\left(\mathrm{N}_{\square}=1161\right)$ to full day $(12 \mathrm{~h})$ numbers. Above - distribution of full day real observations of $N_{\square}(2130)$ raptor birds, below - the distribution above in cumulative form and recalculation of $N_{\square}$ (1161) 6.00-11.00 observed individuals into full day value $N_{\square}$ (2229 ind.).

1.2. Corrected value, according to the recommendations given in 1.1., of the daily number of birds is treated as representative for a pentade (five-day period, counted from the beginning of the year - January $1 \mathrm{st}$ ), thus estimated pentade value is: 5 * daily value.

The example (1) continued: $5 * 240=1200$, so we assume that 1200 indiv. were recorded in the monitored area in this pentade (out of these 960 indiv. on the days other than the observation day).

1.3. Number of birds in pentades empty of observations were interpolated from neighbouring pentades with observations. 


\section{Table 5}

Numbers of raptors observed on 76 wind farm localities and parameters of observations. $F$ - number of localities where at least one individual of the species was observed (\% - percent of all farms studied), $N$ - No. of individuals observed, Frequency at all and farms with at least one observation of the species, Distance - average distance of observation, Flight level,$-<”-$ below the rotor, "=" - within the rotor, ,>" - above the rotor.

\begin{tabular}{|c|c|c|c|c|c|c|c|c|c|}
\hline & \multicolumn{2}{|c|}{ Farms } & \multirow{2}{*}{$\begin{array}{c}\text { Indiv. } \\
N\end{array}$} & \multicolumn{2}{|c|}{ Indiv./Farm } & \multirow{2}{*}{\begin{tabular}{|c|} 
Distance \\
$m$ \\
\end{tabular}} & \multicolumn{3}{|c|}{ Flight level } \\
\hline & $F$ & $\%$ & & N/all & $N / F$ & & $<$ & $=$ & $>$ \\
\hline Buteo buteo & 76 & 100 & 10143 & 133.5 & 133.5 & 34 & 72.0 & 22.0 & 5.2 \\
\hline Accipiter nisus & 73 & 96 & 669 & 8.8 & 9.2 & 107 & 84.1 & 15.0 & 0.9 \\
\hline Accipiter gentilis & 63 & 83 & 252 & 3.3 & 4.0 & 274 & 81.0 & 15.5 & 2.8 \\
\hline Falco tinnunculus & 62 & 82 & 797 & 10.5 & 12.9 & 100 & 88.0 & 9.4 & 0.6 \\
\hline Circus aeruginosus & 59 & 78 & 1488 & 19.6 & 25.2 & 175 & 92.1 & 7.1 & 0.6 \\
\hline Buteo lagopus & 55 & 72 & 458 & 6.0 & 8.3 & 250 & 72.5 & 22.5 & 1.1 \\
\hline Circus cyaneus & 51 & 67 & 255 & 3.4 & 5.0 & 245 & 94.5 & 4.7 & 0.8 \\
\hline Haliaetus albicilla & 50 & 66 & 433 & 5.7 & 8.7 & 258 & 56.1 & 35.6 & 7.9 \\
\hline Falco subbuteo & 34 & 45 & 90 & 1.2 & 2.6 & 85 & 73.3 & 24.4 & 0.0 \\
\hline Circus pygargus & 33 & 43 & 238 & 3.1 & 7.2 & 246 & 84.0 & 11.8 & 4.2 \\
\hline Milvus milvus & 31 & 41 & 286 & 3.8 & 9.2 & 161 & 59.1 & 35.7 & 5.2 \\
\hline Pernis apivorus & 27 & 36 & 83 & 1.1 & 3.1 & 128 & 57.8 & 36.1 & 6.0 \\
\hline Aquila pomarina & 21 & 28 & 384 & 5.1 & 18.3 & 357 & 53.1 & 32.0 & 14.8 \\
\hline Pandion haliaetus & 11 & 14 & 11 & 0.1 & 1.0 & 254 & 63.6 & 36.4 & 0.0 \\
\hline Falco peregrinus & 8 & 11 & 9 & 0.1 & 1.1 & 131 & 66.7 & 22.2 & 11.1 \\
\hline Falco columbarius & 8 & 11 & 11 & 0.1 & 1.4 & 165 & 81.8 & 9.1 & 0.0 \\
\hline Milvus migrans & 6 & 8 & 8 & 0.1 & 1.3 & 187 & - & - & - \\
\hline Aquila chrysaetos & 6 & 8 & 36 & 0.5 & 6.0 & 362 & 88.9 & 11.1 & 0.0 \\
\hline Falco vespertinus & 3 & 4 & 4 & 0.1 & 1.3 & 149 & - & - & - \\
\hline
\end{tabular}

1.4. Estimated total number of birds of each species observed during one year is the sum of corresponding numbers recorded during all pentades (1st to 73rd pentade). Numbers per season are calculated as well. These numbers can be illustrated in the report using the appropriate graph (see later at Fig. 11): it gives at glance a picture of all year species dynamics at the studied site.

2. Probability of collision of an individual bird

2.1. The probability of potential collision depends on two factors: how far from the planned/imaginary turbine the bird was observed (distance coefficient) and behaviour of the bird (level coefficient) - whether it was flying or sitting on the ground/ low vegetation/electric poles etc. Three levels of flight are recorded - below, within and above the rotor swept, thus only birds recorded within the rotor swept are endangered at the moment (Table 5). It is simplification, as flying bird can change its flight level and even birds sitting on the ground can after a while cross the rotor swept level. Still, we must accept that levels given are samples of the real distribution in the air - thus this array is a kind of index of the flight situation (Figs 4 and 5). Field data clearly showed that the distance and flight level coefficients give the probabilities 
varying very much according to species behaviour in the given locality. The less birds were observed within the rotor swept, the lower probability of collision is.

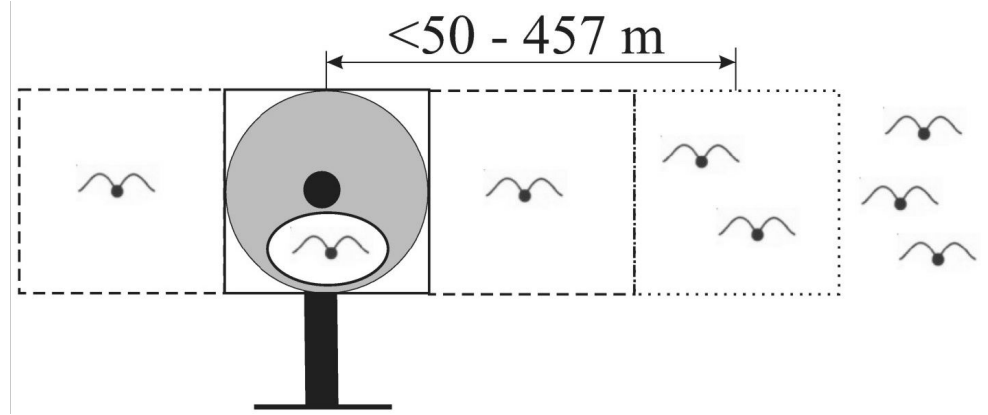

Fig. 4. Birds flying within and in a distance of the rotor swept (average distances of observed flights are given)
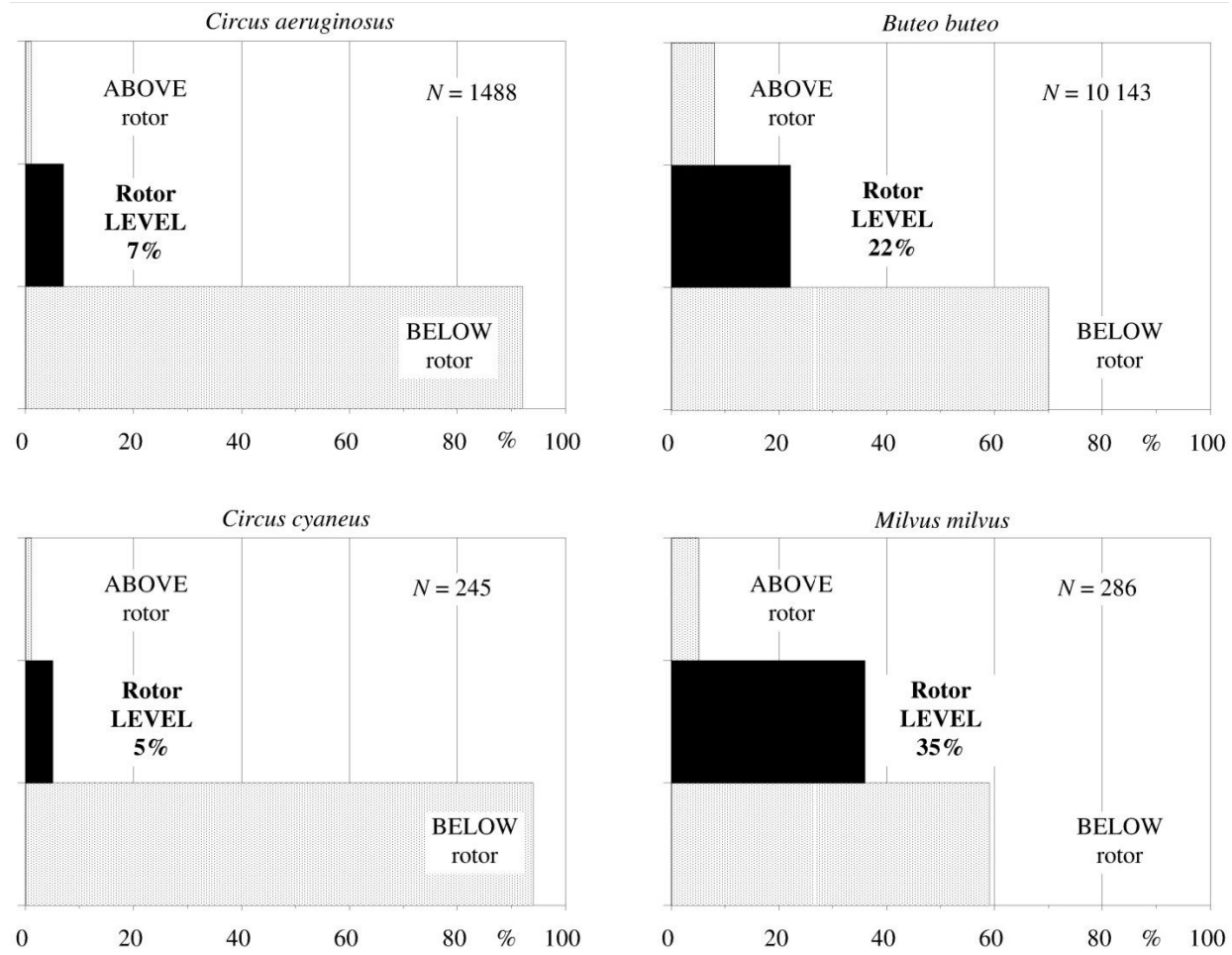

Fig. 5. Average levels (at 76 of locations studied) of flight of different raptor species. $\mathrm{N}$ - numbers of individuals observed).

2.2. As indices given above represent the probability of an individual bird to fly through the space depending on the rotor diameter, it is necessary to apply a correction coefficient, from the square to a circle -0.785 . Additionally, position of the rotor 
changes all the time according to wind direction in relation to a flight course (Fig. 6), therefore another correction should be made - if we assume average, $45^{\square}$, position the correction factor will be equal to 0.4929 . The corrected value is the probability that the bird will pass through the swept area IF the bird will not actively avoid to do so.

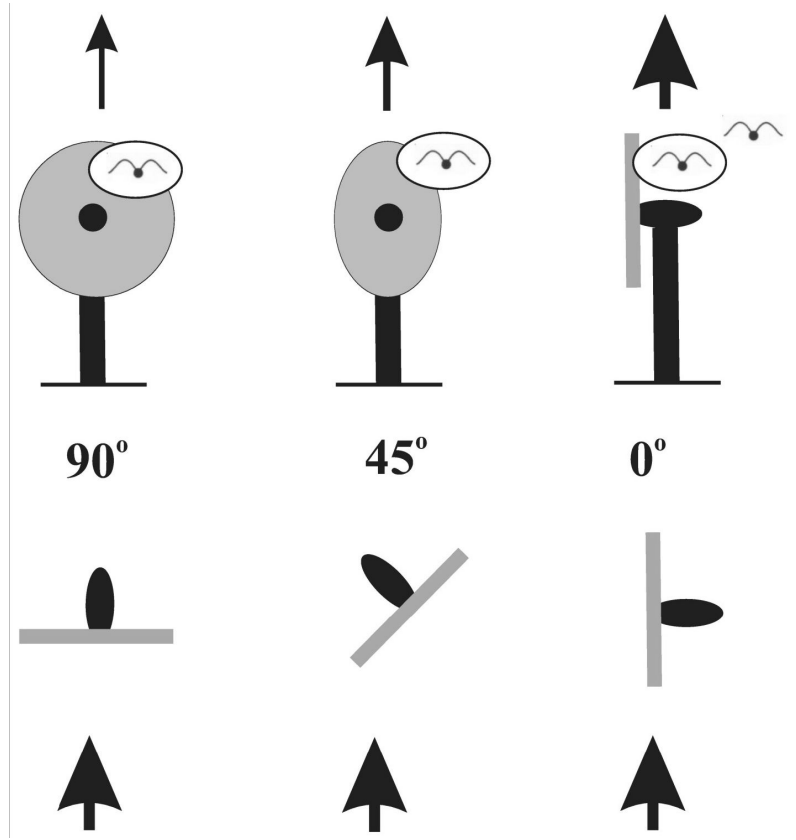

Fig. 6. Different aspects of the rotor in relation to the direction of the bird flight

2.3. Probability calculated above is the starting point to introduce the most important parameters of collision risk: (1) active avoidance rate (behavioural property of the bird) and (2) hitting probability if bird passes through the rotor swept (Fig. 7). These parameters are frequently mixed and combined into one probability called "avoidance rate" or even combined further with so called "the barrier effect" (avoidance of flying through the wind farm as a unit). Such generalizations could make interpretation of published "avoidance rates" highly ambiguous. If one tries to compare differently defined avoidance rates with actual number of collisions, conclusions could be contradictory. In the present paper collision risk is defined as: active avoidance rate * hitting probability

As active avoidance rate for the species is difficult to assess directly, it is assumed to be at the level of 0.99 (99\%) - thus exposure to be hit - 0.01 (earlier mentioned $U$ value), while proportion of birds, which potentially could be hit by the rotor is given as 0.15 for large birds - like e.g. raptors of average size (according to the levels given by Band et al. 2007), 0.05 for smaller birds - like the Starling, Song Thrush etc. and 0.01 for the smallest passerines. Thus the overall probability of collision could be between 0.0001 to 0.00015 ( 1 to 15 individuals per 10000 potentially crossing the swept area of the turbine). 


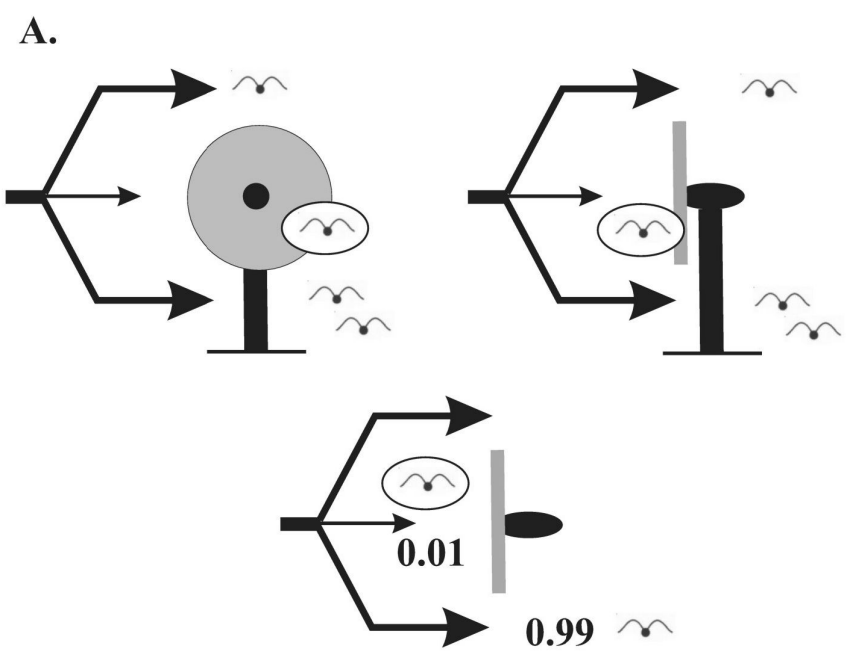

B.

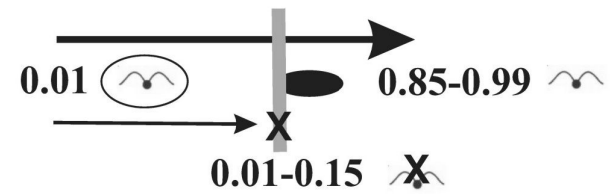

Fig. 7. Active avoidance of the rotor by birds. A. missing the rotor by above or below track and missing the rotor by side displacement. The level of avoidance $U=0.99, P=0.01$ (see text); B. out of $P$ birds flying through the rotor swept area (0.01) only $0.01-0.15$ are hit and 0.85-0.99 pass through safely.

3. The final estimation of collision risk of the species at the single turbine is: estimated number of individuals * estimated collision rate

Total collision rate at the turbine is the sum of all individual species estimates. Total for the farm is the sum of all recorded species estimates for all turbines. However, as estimations based on a low number of recorded individuals are vulnerable to accidental variation, these are calculated when more than 10 individuals of the species were observed. Rare birds are discussed separately, comparing observations at the given locality with average results for many other localities known (see Table 6).

4. Because of rapid technological development it is quite common that preliminary plans can indicate certain type of the turbines, while with new solutions becoming accessible they can be changed to another one. The most common is a change of the turbine power and dimensions - the hub height and the rotor diameter. If, e.g. 2 MW turbines of $90 \mathrm{~m}$ hub height and $90 \mathrm{~m}$ rotor diameter were planned, the observer noted flying birds at three layers: "below the rotor" - up to $45 \mathrm{~m}$, "within the rotor swept" - 45 to $135 \mathrm{~m}$ and "above the rotor" - above $135 \mathrm{~m}$. If the parameters of turbines were later changed, e.g. to $3 \mathrm{MW}$ with $120 \mathrm{~m}$ hub and $120 \mathrm{~m}$ rotor diameter, the problem arises how much such change influenced the estimations. Recalculations are still possible according to information presented in Figure 8. 


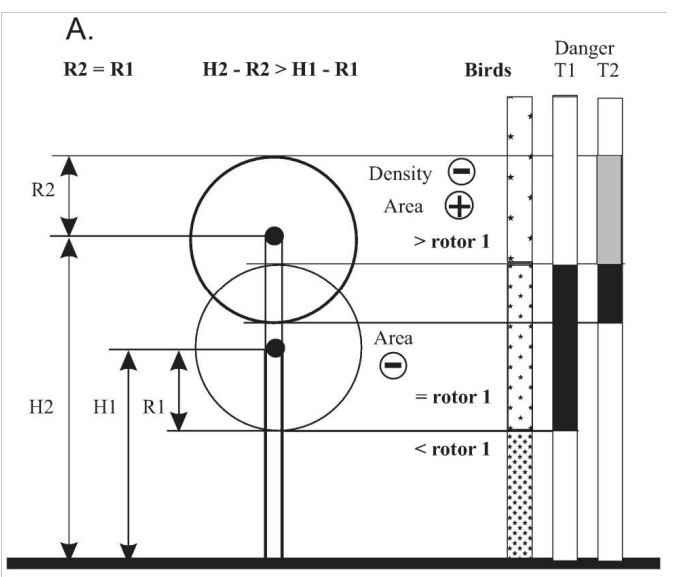

B.

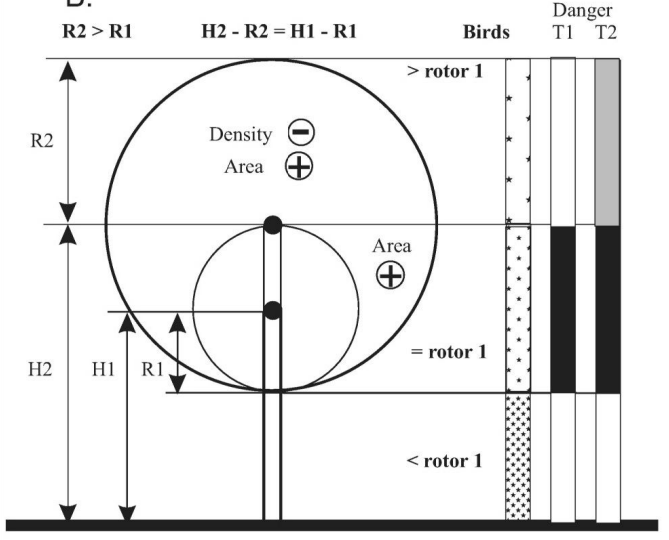

C.

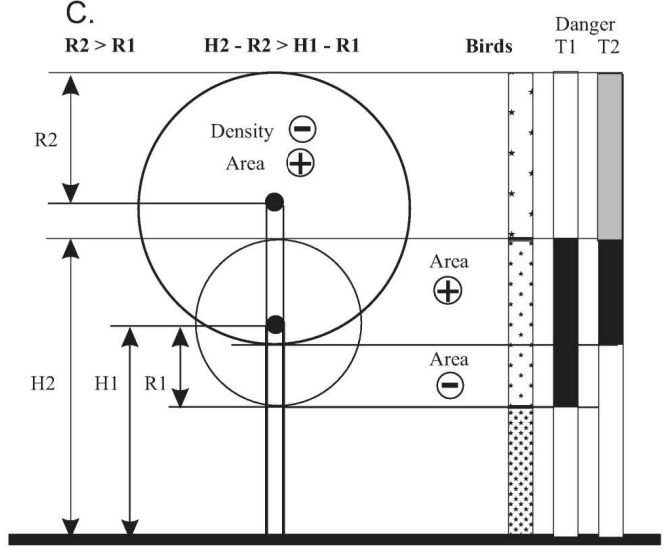

Fig. 8. Effects of changing turbines parameters (H1 - H2, R1 - R2). A and B - border cases: A. only the hub height was changed, B. the hub height and the rotor diameter were changed, but the lower rotor swept level lasted the same, C. the most common and complicated situation. Three levels of birds densities are shown as well as risk levels (black - many birds, swept are thus danger, grey - less birds, swept area, white - out of the swept area thus no danger). Areas with growing $(+)$ and reduced (-) risk are pointed. 
During such changes two processes should be distinguished: (1) change of the swept area (larger rotor diameter) that increase possibility of the bird to be hit (but it is possible that this dependency is not linear - thus calculations could be even more complicated) and (2) moving a part of the swept area higher, where as a rule less birds move (cf. Fig. 5). Usually resulted changes are not bigger than $20 \%$ and influence is not important, especially that we must have in mind that all values we present are estimations, indices rather than values with really delimited accuracy.

Table 6

Estimates of the collision risk of raptors - calculation are based on data from 76 planned wind farms localities in Poland. $M$ and $S D$ - average and standard deviation for all localities. Estimation of years - how many years is needed for one collision per turbine (or - how many turbines is needed to kill one individual in one year).

\begin{tabular}{|l|c|c|c|c|c|}
\hline & \multicolumn{2}{|c|}{ Collision risk per turbine } & \multicolumn{3}{|c|}{ Estimation of years } \\
\cline { 2 - 6 } & $M$ & $S D$ & Pes. & AVG & Opt. \\
\hline Buteo buteo & 0.0470 & 0.0056 & 21 & $\mathbf{2 1}$ & 22 \\
\hline Milvus milvus & 0.0075 & 0.0145 & 70 & $\mathbf{1 3 3}$ & 1134 \\
\hline Aquila pomarina & 0.0048 & 0.0075 & 110 & $\mathbf{2 0 6}$ & 1576 \\
\hline Buteo lagopus & 0.0045 & 0.0086 & 135 & $\mathbf{2 2 4}$ & 667 \\
\hline Haliaeetus albicilla & 0.0044 & 0.0077 & 140 & $\mathbf{2 3 0}$ & 636 \\
\hline Circus aeruginosus & 0.0041 & 0.0059 & 166 & $\mathbf{2 4 6}$ & 476 \\
\hline Falco subbuteo & 0.0034 & 0.0049 & 181 & $\mathbf{2 9 7}$ & $>5000$ \\
\hline Pandion haliaetus & 0.0027 & 0.0023 & 223 & $\mathbf{8 4 3}$ & 1063 \\
\hline Pernis apivorus & 0.0027 & 0.0040 & 212 & $\mathbf{3 6 5}$ & 1314 \\
\hline Accipiter gentilis & 0.0016 & 0.0042 & 339 & $\mathbf{6 2 8}$ & 4300 \\
\hline Aquila chrysaetos & 0.0013 & 0.0022 & 278 & $\mathbf{7 9 7}$ & $>5000$ \\
\hline Falco peregrinus & 0.0013 & 0.0023 & 298 & $\mathbf{7 6 6}$ & $>5000$ \\
\hline Accipiter nisus & 0.0012 & 0.0017 & 572 & $\mathbf{8 0 6}$ & 1369 \\
\hline Milvus migrans & 0.0012 & 0.0014 & 369 & $\mathbf{8 1 4}$ & 5000 \\
\hline Falco tinnunculus & 0.0011 & 0.0019 & 592 & $\mathbf{9 2 9}$ & 2150 \\
\hline Circus pygargus & 0.0009 & 0.0027 & 483 & $\mathbf{1 1 6 1}$ & $>5000$ \\
\hline Circus cyaneus & 0.0007 & 0.0030 & 554 & $\mathbf{1 3 7 9}$ & $>5000$ \\
\hline Falco columbarius & 0.0001 & 0.0003 & 2699 & $\mathbf{9 1 6 4}$ & $>10000$ \\
\hline Falco vespertinus & - & - & - & - & - \\
\hline
\end{tabular}

\section{Main factors influencing accuracy of estimations}

Estimates, as the results of processing not strictly exact observation data, and based on the assumptions are always indices rather than values and they are biased in different ways. There are two kinds of biases that have different influence on the results: directional (making the estimate higher or lower) and not directional, being rather information noise, that makes variance larger, thus less informative. In the pre-investment monitoring the first kind of biases is more risky as it can make the final conclusions either too pessimistic or optimistic. 
In the procedures of field observations and evaluation of the results both types of biases can occur:

1. Field data (comments applicable to any type of ornithological monitoring based on the sampling)

1.1. number of controls and observation duration (bias: not directional) - the more controls and the longer observation time the more precise results we will get. However, we must be aware that any sampling, especially during migration period is much biased. Even sampling as frequent as every 5 days can result in the highly fluc-
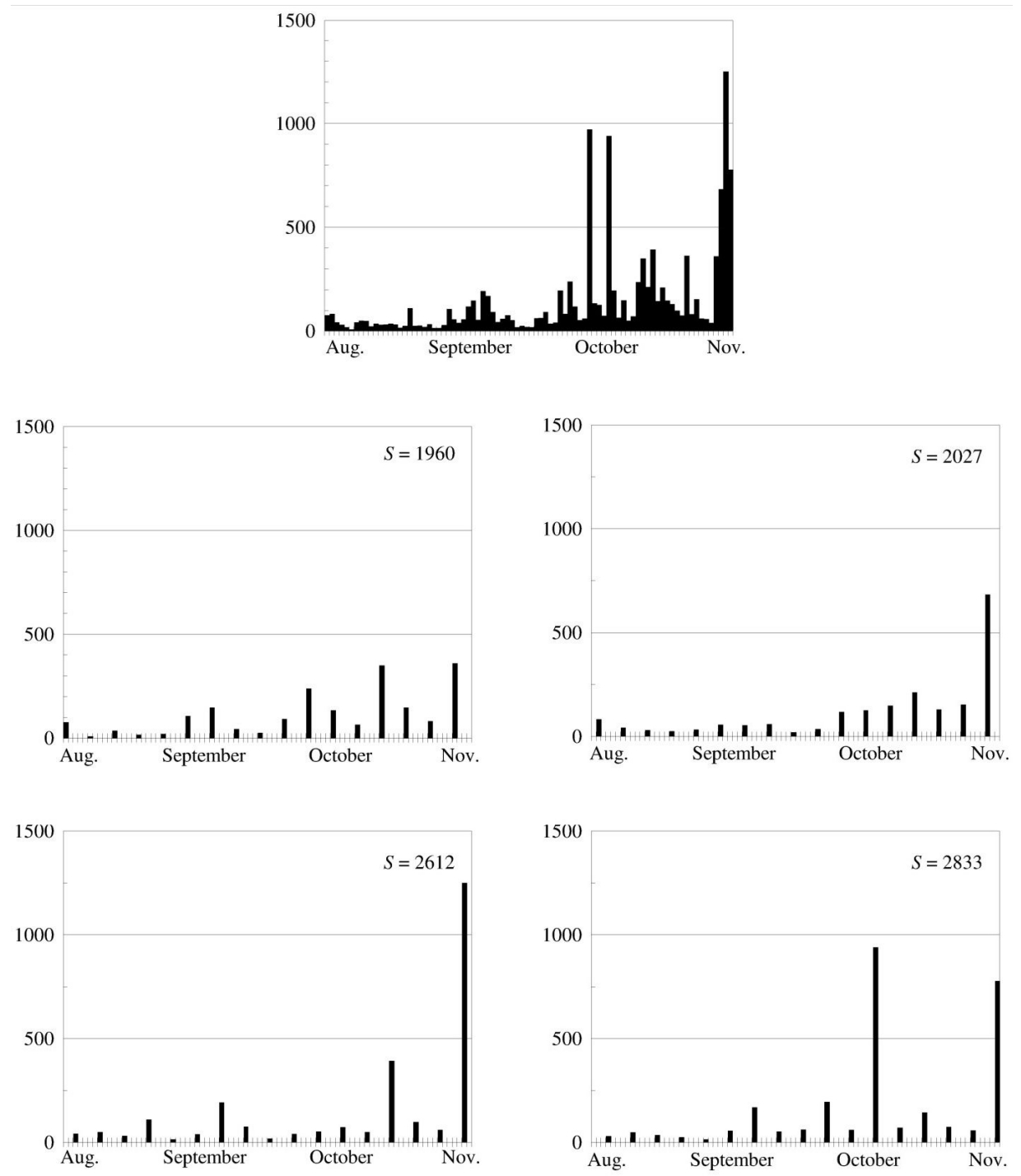

Fig. 9. Example of sampling results in a bird migration period. The top pane - real numbers of migrants by days. Four panes below show resuls of simulation that sampling was done every 5 th day, but starting from subsequent days (13, 14, 15, 16th August). Resulting numbers vary from 1960 to 2833 ! 
tuating data - a typical example is presented in Figure 9. More frequent sampling reduces bias caused by accidental observations, e.g. observation of an exceptionally big flock of some gregarious species as starlings, corvids or fieldfares.

1.2. part of day observation can influence results because of diurnal pattern of birds' behaviour (eliminated in this system - see Fig. 3, as the correcting activity coefficient is adapted to the standard observation time).

1.3. variable weather conditions (bias: not directional or increasing variation) still it is impossible to precisely estimate their influence and propose correction of the results. Possibly in the future some technical solutions as radar, infrared or acoustic instruments will be helpful.

1.4. migration of birds on very high level or far from the observer (lowering number of observed birds, but not influencing collision rate) - missed birds have no chances to be killed.

2. Calculation assumptions

2.1. recalculation from a few hours to a whole day (bias: not directional; in different parts of a season either over- or underestimating the data) - setting equal number of light hours for a whole season means that in the border pentads recalculations give lower values than in the middle part of the season.

2.2. recalculations from days to pentad values and interpolation between pentads (bias: not directional, but tends to give less precise values) - not avoidable when applying the sampling method.

2.3. calculation of probability that the bird will be in potential risk of collision with rotor (to some extent limited by using the rotor aspect coefficient) - see Figure 6: the dangerous area is the largest if the bird flies perpendicularly to the rotor, the smallest if it flies parallel to the rotor.

\section{Verification of the method}

Published data and the results of a few Polish post-building studies show that variation in collision numbers is high and starts from 0 to reach over 60 victims per turbine a year (Hötker et al. 2006). Additionally, there is a huge variation in the technologies used in the monitored farms (power, size of hub and rotors, construction of the hub, distances between turbines), locality properties (sea coast, inland, mountain ridges etc.), size of the farm and methodology of post-building monitoring studies (e.g. observation time span and sampling method). This makes comparisons difficult (op.cit.). However, a few examples could be cited:

- USA, Minnesota - 73 turbines (located at distances 90-180 m), two observation years and only 11 birds killed (Higgins et al. 2007);

- altogether 4724 turbines on 18 farms (Sterner et al. 2007 - data from 14 papers, different countries): yearly level of raptor victims per turbine -0.00 (9 farms) $0.012-0.023-0.036-0.05-0.007-0.1-0.176-0.48$ (values 0.023 and 0.05 are from Altamont Pass); for comparison - estimations with the method presented here at 71 localities in Poland: the Buzzard Buteo buteo - 0.032, Sparrowhawk Accipiter nisus -0.001 . 
- in Poland: farm of 9 turbines 2 MW situated at the sea coast - 4 months of every day controls during migration time - victims: none; farm of 24 turbines close to the sea coast - monitoring: March - December - 1 Feral Pigeon; farm of 20 turbines, three years monitoring - dozen or so victims, but two raptor birds (Zieliński et al. 2008; pers. comm.).

Despite the examples are not too representative of the problem, distribution of reported data could be helpful. Figure 10 presents distribution of reported collisions rate (no. of victims per turbine per year) and for comparison - results of estimations with the method described here on 71 localities in different parts of Poland. The agreement of estimations and actual collision rate distribution is high. Differences in the course of both curves suggest that estimations are overestimated compared to real losses, thus they are cautious enough and can be used for prognoses of collision risk at certain localities.

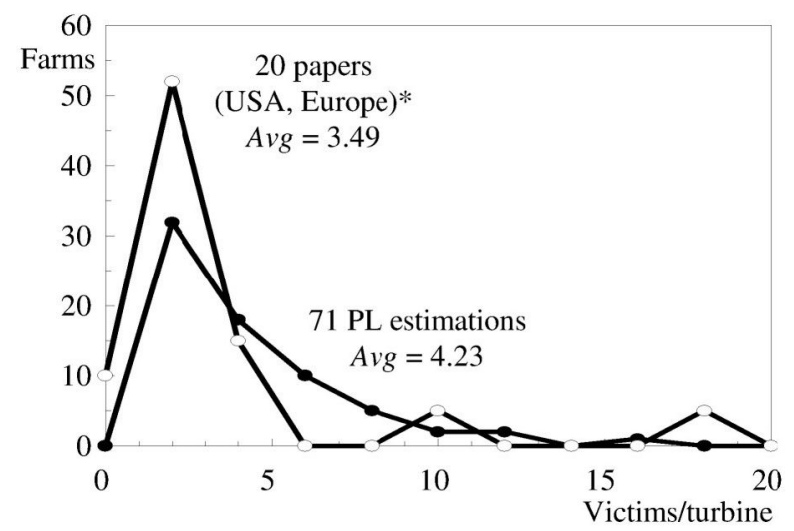

Fig. 10. Comparison of distributions of real numbers of victims (per 1 turbine) from 20 papers (* USA, Europe - after Hötker et al. 2006) and 71 results of estimations made in Poland using described method.

\section{BASICS OF INTERPRETATION OF RESULTS AND FINAL PROGNOSIS}

\section{Output from the programme WINDFARM RISK}

The programme WIDFARM RISK gives several output files that imported into a spreadsheet are a basis for discussion and evaluation of potential risks for the observed species. The most general are species profile showing its occurrence at the spot and air space utilisation. Other information show flight direction rose. For every species a complete list of its observations is available. All these data are available either for the whole year (Fig. 11) or for each season. The same sheets are produced separately for the species of the high conservation concern. They are the basis for the general risk analysis as well as for seasonal ones - the set of data covering breeding time is particularly important as it is information on the risks to the local breeding population and could point at special risks connected with the possible loss of terri- 
tory. Concentration of risks during migration suggests putting special attention to a local migration streams. Accidental observations of the species point out at secondary value of the locality for that species.
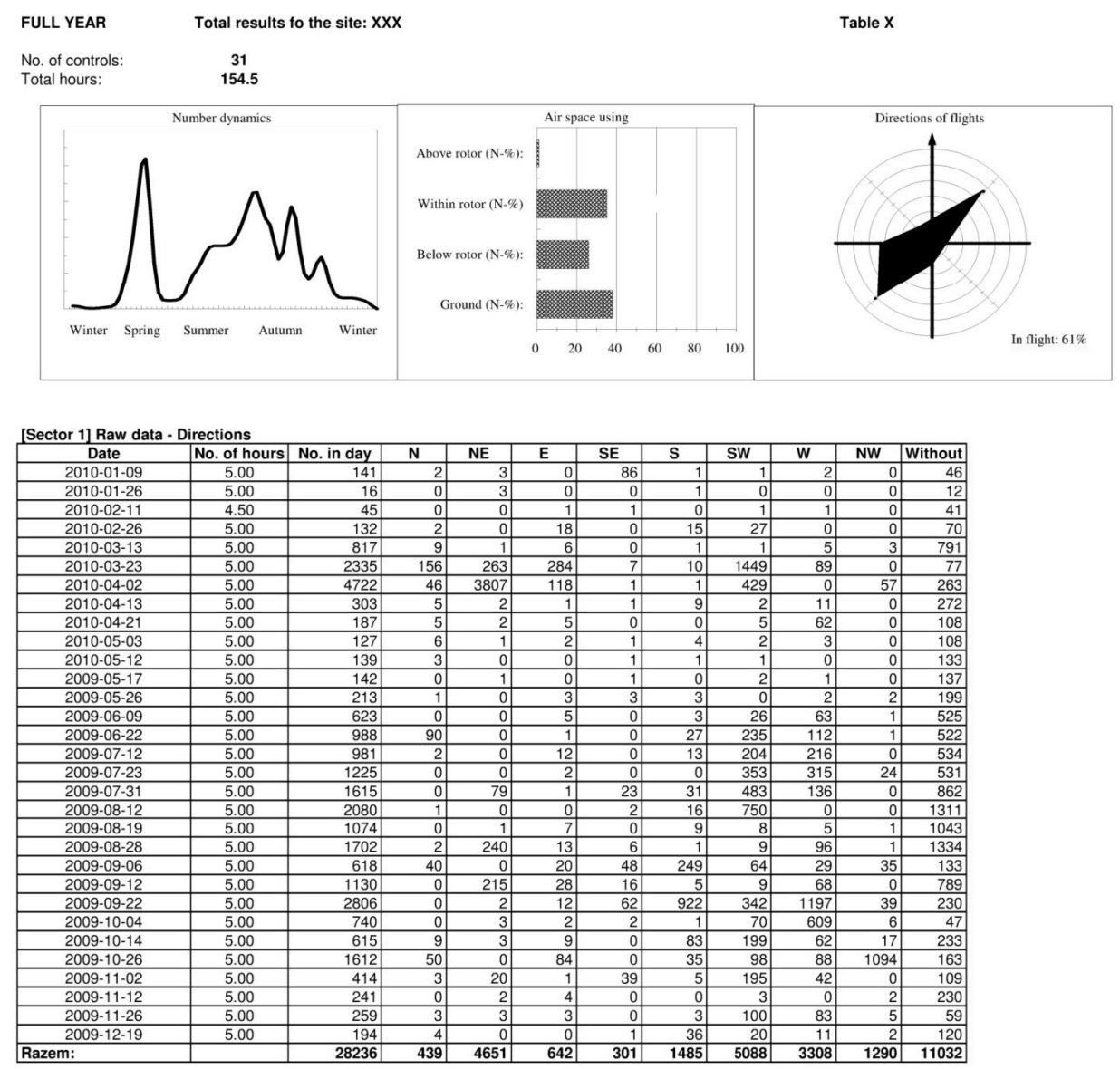

$\begin{array}{lcc}\text { [Sector 2] Parameters } & & \\ \text { Ground (N-\%): } & 2496 & \mathbf{3 8} \\ \text { Below rotor (N-\%): } & 1685 & \mathbf{2 6} \\ \text { Within rotor (N-\%) } & 2251 & \mathbf{3 5} \\ \text { Above rotor (N-\%): } & 66 & \mathbf{1} \\ \text { Directional (N-\%): } & 17204 & 61\end{array}$

Fig. 11. Example of total results of the full year monitoring - part of an output from the WindRisk programme.

\section{Parametric evaluation of the planned farm}

Apart from the analyses of species specific risks very, general valuation of the site is also important. The more general valuation is possible when the comparison among different parameters of the certain farm in relation to other potential sites for 
building wind farms is available. The basic idea of this parametric evaluation is to (1) prepare different parameters' distributions from the already studied localities of the wind farms, (2) compare the parameter value of a newly monitored location in relation to the known distribution, (3) give the ranking scores and, finally, summarize scores into a general valuation index. The selection of the parameters for evaluation is somewhat subjective (though based on the experience) and disputable, but still ranking is a common procedure in most evaluations as it is less person-dependent than individual judgement.

The actually used parametric valuation table is an effect of previous analyses and is based on the data from 71 studied localities (next 50 will be evaluated and added to this table - see Figure 12 as an example). The table contains four groups of parameters: (1) General - number of observed species, number of individuals (per 1 hour of observations), frequency of birds flying at the risk level (\% of birds at the rotor swap level), (2) Seasonal - estimated collision rate for subsequent seasons, (3) Important species - estimated collision rates for raptors and species listed in EU Directive App. I, (4) Breeding - species breeding within location and special concern species breed-

Parametric valuation table

Farm XXX

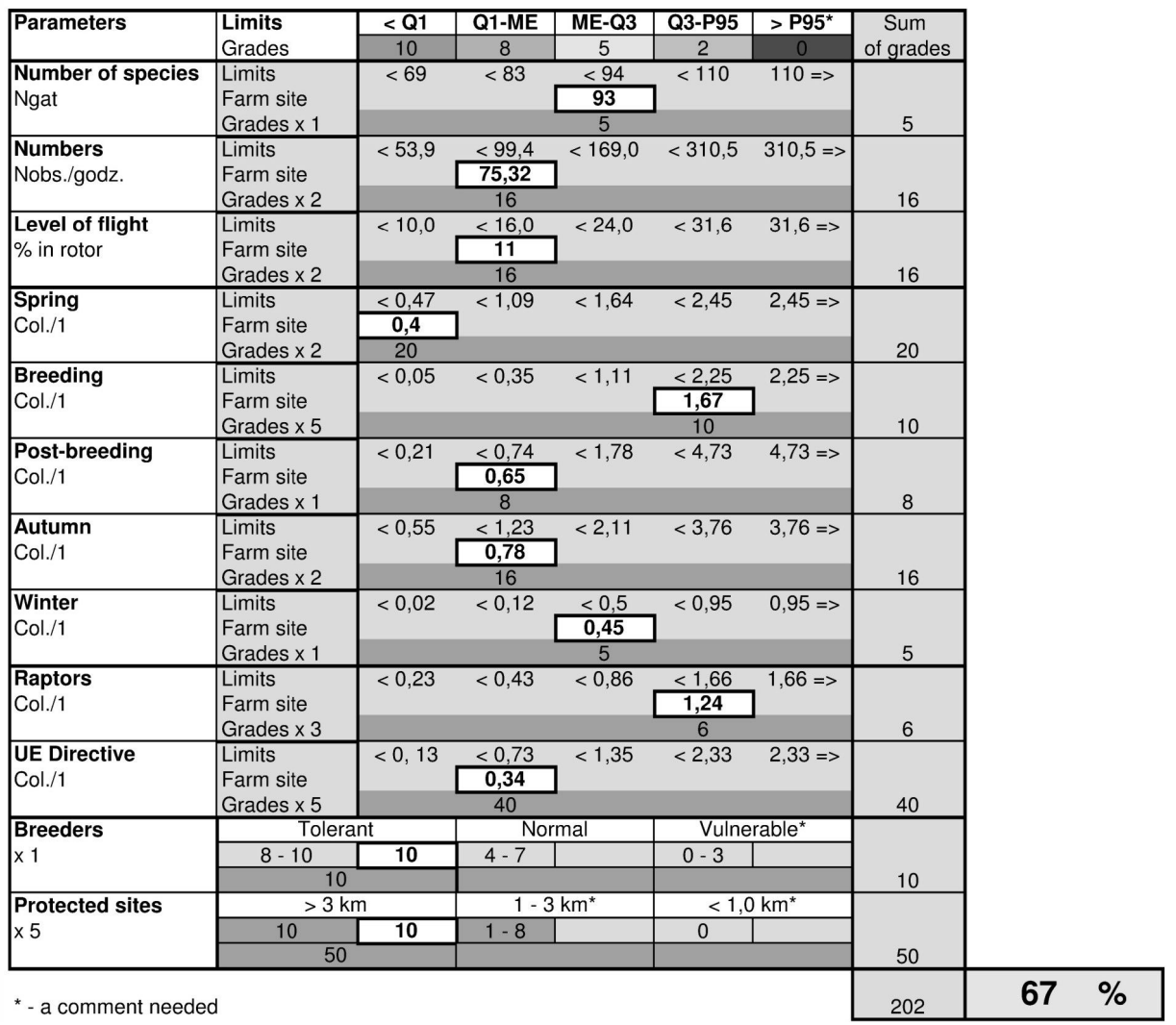

Fig. 12. Example of the parametric valuation table. White rectangles show parameters values for the studied farm in relation to general distribution of values for 76 farm localities in Poland (shadowed). 
ing in the vicinity. All parameters of the studied location are ranked automatically from 0 to 10 scores depending on relation of its parameter value to the overall distribution: "Q1" (below1st quartile) - 10, "Q1-M" (between 1st quartile to median) - 8, “M-Q3" - 5, "Q3-P95" (3rd quartile to 95 percentile) - 2 and "P95" - 0.

Different parameters have different weights as their general influence is according to the expert experience differentiated: e.g. in general group "Number of species" has lower weight than others because it is more dependent on the observer characteristics. In the group of the seasonal parameters the risk value in the breeding time is much more important than in other seasons as it reflects potential influence on local population. Such expert quantification of scores is commonly used in general bird conservation valuations, e.g. SPEC 1 ...3 classification of species by BirdLife or in the valuations in the NATURE 2000 sites. Future experience in pre-building monitoring will surely bring some changes and updates to the scoring system.

General valuation output in this method is a value expressed in the percent of the highest possible score that is in this table equal to 300 .

In some cases high values can result from accidental situations, e.g. observation of a single, but huge flock of common birds, additionally flying at the level of the rotor swept or extremely high dominance of one, common species, as Starlings Sturnus vulgaris (frequent case). So, the extreme values/scores should be checked and additionally discussed.

Relations between the valuation of the seasons can give important suggestion for discussion of the results, especially pointing whether the result should be related to the local or to general population of broad source territories that can be estimated according to knowledge on bird migration and densities in different parts of Europe (Hagemeijer and Blair 1997).

\section{"Risk cumulation" and the "barrier effect"}

The term "risk cumulation" is used in different meanings: (1) the sum of negative effects caused by every single turbine in the wind farm, (2) rather exponential than linear growth of negative effects when the farm became larger and larger, (3) the sum of effects caused by several farms in the defined area or even at the route of migration, and finally, (4) summarising negative effects to the population and originating from different human activity.

The single turbine in any place could have its own negative effect on birds and this is estimated earlier in the process of evaluation of risks caused by the farm. Negative effects can influence both breeding and migrating birds. For most of the species nesting in open habitats any pronounced, high element in a vicinity could act as a strange, potentially dangerous item. In the natural habitats this could be a high tree or even not too high bush or electric line - being potential hunting post for raptors or nest robbers. The same applies to the wind turbine. Usually the single wind turbine is treated by nesting birds as such potential danger. Different species have differentiated distance at which they feel safe enough and this distance only rarely is larger than $200 \mathrm{~m}$. Some species totally ignore turbines and nest close to them, even sometimes they are attracted and nest around the hub base. 
In the modern and small farm, where the distances between turbines are large (as a standard - 5 rotor diameters) a cases that influences grow more than a sum of disturbances caused by the single turbine are negligible, so the "cumulation" of risks practically does not exist (case 1 above). However, if the distances between turbines are low (old fashioned farm design) or the area covered by the farm grows too much the result disturbance could be higher than the sum of individual influences (case 2 above). If second possibility occurs - too large area covered by the wind farm is planned - the problem of cumulation could be solved by cutting the area by stripes of land with no turbines; small groups of turbines do not make the risk cumulated more than sum of single influences. And here we can start to discuss on how many turbines per the area are safe enough to accept wind turbines' development within the administration or geographical territory (case 3 above). There are two aspects here - influence on the local breeding population and on overall species geographical population. For well-being of the local population it is necessary to save nesting/feeding grounds large enough and the collision risk should be at the level that potential reproduction could cope with. These needs are species specific and differentiated very much, but unfortunately poorly known. There is no better advice than intensive scientific work on this problem. The problem of migration route "cumulation" is rather apparent than real - chance that the individual will pass several times through the wind farm is at the level of a lottery hit. We can discuss only the total number of victims of the species in relation to the global (e.g. European) population size. In most of species such losses in relation to the population size are negligible and only very few species are of such high conservation concern that they must be discussed separately not in the chapter about "cumulation".

Cumulation of effects caused by different sources of risks is purely theoretical problem at contemporary level of ecological knowledge - in most species we do not know even basic population ecology parameters or the data are close to anegdotic separate papers are based on differentiated methods and made in various circumstances.

Similar problem is with discussion of the "barrier effect" that is defined as (1) a negative influence of wind farms on reproduction rate of birds breeding close to the farm and forced to make longer feeding flights because the farm is located between the nest and the feeding ground and adult bird must do longer flights than earlier and thus, loose more energy that can be used for better feeding chicks. Despite for separate pairs it can be possible, the generalization is unsound because it assumes low adaptation abilities of birds (that is clearly not the case) and/or an unique location of every nest in a space (and additionally, that the habitat capacity is fully exploited that, too, is doubtful very much). Others claimed that the "barrier effect" is important for migratory birds - pointing at the same "energy loss" when migrants try to avoid crossing wind farm field because this is a barrier for them. It is true that many migrants moving at lower altitudes during daytime react before crossing big field of turbines and try to pass it around or above (many birds below the rotor swept area). This behaviour do not need too much extra energy, if we take under consideration that daily sectors of the journey are of length of hundreds kilometres. In relation to thousands of kilometres of a flyway and ability to correct hundreds of kilometres of side 
wind displacements claimed "additional energy loss" is only theoretical. Finally, at a local scale leaving the corridors/space free of turbines within huge wind farms could be applied. Farms or groups of turbines built a few kilometres apart practically do not cause any extra energy expenditure to migrants, thus even from a very cautious point of view they are safe to birds.

\section{Ornithological properties of the wind farm location and NATURE 2000 sites}

Creation of the NATURE 2000 sites was intended to protect the European areas, which are the most important from the nature conservation point of view. Thus, if planned human activity could disturb them a careful discussion of plans should be performed. The most important is to assess whether defined investments could influence the most important ecological properties of the site in question. As there are two kinds of sites protected within the NATURE 2000 system - habitat and bird areas, different aspects of potential disturbances need to be taken under consideration. Generally, wind farms are potentially less harmful for habitat sites - this is obvious that turbines cannot be situated on the protected valuable habitats, as e.g. wetlands or xerothermic slopes with unique vegetation type, while the bird fauna, if not especially rich, could be of secondary interest and analysed as usual in the evaluation routine. The bird NATURE 2000 sites and its direct vicinity need to be more carefully analysed than common localities. It does not mean, however, that the location of wind farms is not possible at all - we need to remember that if the protected site is large, e.g. of the size of more than hundred kilometres long and tens kilometres wide, then inside of its area there are some rich and some poor in birds patches. Location of not too big farm at this poorer areas could be not too harmful to the birds, while sound from the local people point of view - gains and risks analysis should give positive output.

Analysis of the situation during the breeding time there must carefully take under consideration both collision risks and breeding disturbances, particularly of the species of greater conservation concern. The analysis should take under consideration such risks even when the planned farm area is outside of the NATURE 2000 site. However, one must know that potential influence depends strongly on the distance between the planned farm to the protected area. The potential influence decreases proportionally to the second power of a distance: potential influence at the distance of $2 \mathrm{~km}$ from the spot is four times lower than at the site or at the distance of $10 \mathrm{~km}-$ 100 times lower, thus here negligible. Practically, there is no bigger chance that the farm can influence the site at the distance of more than $5 \mathrm{~km}$, even that sometimes individuals nesting there will visit the farm area. In a few exceptions, however, it could be a case because of local behaviour of birds, but this is controlled during the observations in a field work.

Out of the breeding season, the discussion of risks to the birds could be as usual, but with exception only when the site was set because of an unique value for migrants - this means migration bottle-necks or exceptionally good feeding/resting/wintering areas of migrants, particularly located at the borders of migration barriers - e.g. sea coast. 


\section{Final evaluation of the wind farm site}

Final conclusion as to the wind farm valuation must be a synthetic estimation of balance of different sources of risks discussed above and gains, as reduction of carbon and toxic gas pollution, local people economic welfare etc. In some cases risks mitigation activity could be suggested to be used when post-building monitoring will report higher negative influences than expected. As mitigation is very species specific, such activity must be adjusted to a special risks recorded at the farm.

\section{REFERENCES}

Band W., Madders M., Whitfield D.P. 2007. Developing field and analytical methods to assess avian collision risk at wind farms. In: Birds and wind farms. Risk Assessment and Mitigation. Edit Quercus, Madrit,

Chamberlain D.E., Rehfisch M.R., Fox A.D., Desholm M., Anthony, S.J. 2006. The effect of avoidance rates on bird mortality predictions made by wind turbine collision risk models. Ibis 148 (Suppl. 1), 198-202.

Erickson W., Strickland D., Young D., Johnson G. 2008. A Summary of Avian and Bat Fatality at Wind facilities in the U.S. NWCC Res. Meeting, Milwaukee, November.

Fernley J. 2008. Birds, wind farms and collision modelling: a study of golden eagles. Unpublished Report, West Coast Energy Developments Ltd, Mold.

Fernley J. 2009. A Review of "Collision Avoidance of Golden Eagles at Wind Farms under the Band Collision Risk Model" by P. Whitfield.

Fernley J., Lowther S., Whitfield P. 2006. A review of goose collisions at operating wind farms and estimation of the goose avoidance rate. Rep. to West Coast Ltd.

Hagemeijer W.J.M., Blair M.J. (Eds.). 1997. The EBCC Atlas of European Breeding Birds. T. \& AD Poyser. London.

Higgins K.F., Osborn R.G., Naugle D.E., 2007. Effect of wind turbines on birds and bats in southwestern Minnesota, USA. In: Birds and wind farms. Risk Assessment and Mitigation. Edit Quercus, Madrit.

Hötker H., Thomsen K.M., Jeromin H. 2006. Impacts on biodiversity of exploitation of renewable energy sources: the example of birds and bats. Edit NABU.

Percival S.M. 2007. Predicting the effects of wind farms on birds in the UK: the development of an objective assessment method. In: Birds and wind farms. Risk Assessment and Mitigation. Edit Quercus, Madrit.

PSEW. 2008. Wytyczne $w$ zakresie oddziatywania elektrowni wiatrowych na ptaki. Szczecin.

Scottish Natural Heritage. 2011. Use of Avoidance Rates in the SNH Wind Farm Collision Risk Model. http://www.snh.gov.uk/docs/A305435.pdf.

Smales I. 2006. Impacts of avian collisions with wind power turbines: an overview of the modellingof cumulative risks posed by multiple wind farms. BIOSIS Research Report.

Sterner D., Orloff S., Spiegel L. 2007. Wind turbine collision research in the United States. In: Birds and wind farms. Risk Assessment and Mitigation. Wyd. Quercus, Madrit.

Tomiałojć L., Stawarczyk T. 2003. Awifauna Polski. Rozmieszczenie, liczebność i zmiany. Edit PTPP „pro Natura”. Wrocław.

Whitfield D.P., Madders M. 2005. A review of the impacts of wind farms in Hen Harriers. Nat. Research Information Note 1.

Zieliński P., Bela G., Marchlewski A. 2008. Report on monitoring of the wind farm impact on birds in the vicinity of Gnieżdzewo (gmina Puck, pomorskie voivodship). (unpublished report). 